\title{
European Green Deal and transport sector development - opportunities or restrictions
}

\author{
Petya Koralova-Nozharova ${ }^{{ }^{*}}$ \\ ${ }^{1}$ Economic Research Institute at Bulgarian Academy of Science, 10003 Aksakov str., Sofia, Bulgaria
}

\begin{abstract}
The study is focused on the possibilities and restrictions for the development of the transport sector of EU member-states with GDP per head significantly lower than the EU average levels, because of the introduction of the European Green Deal. For the purposes of the research, there are used the methods of quantitative and qualitative analysis, as well as statistical analysis. In the publication, it is examined also the status quo of the European transport system in accordance with the provisions of the European Green Deal and the European policies for the development of the transport sector till 2030 and 2050. Special attention is paid to the energy dependence of the transport modes on fossil fuels, as well as the level of digitalization of the transport sector, the obstacles for operation of sustainable multimodal transportation services and the danger of imperfect market structures emergence in the field of transport in the less developed regions in EU.
\end{abstract}

\section{Introduction}

Climate changes in the last decades set the necessity of significant transformations of various economic sectors on global, European, national and local level. In compliance with the provisions of the Paris Agreement from 2015 [1] for restricting the increase of the global annual temperature with $1,5^{\circ} \mathrm{C}$, at the end of 2019 the European Commission introduced the European Green Deal (EGD). It is adopted as the new economic growth strategy of Europe, a prerequisite for job creations and achieving climate neutrality. In order to meet the above mentioned priorities, Europe needs to pay serious attention to the future development of the transport sector, especially to the transport systems of EU member-states, whose GDP per head is significantly lower than European average levels. This is necessary first, because onefourth of the greenhouse gas emissions in the atmosphere are caused by the transport sector and the observed trends are of increase in their volumes in the next years. For example, $72 \%$ of the emissions are caused by the road transport, $14 \%$ - by the air transport, $13 \%$ - by the waterborne transport (inland waterway and maritime) and 1\% - by the railway transport [2]. On second place $-94 \%$ of the consumed energy by the transport sector is from petrol, as $84 \%$ of the petrol is imported to the continent, which fact makes Europe energy dependent on third countries and threatens its energy security [3]. This means, that in order to be

\footnotetext{
* Corresponding author: p.koralova@iki.bas.bg
} 
achieved $90 \%$ of decrease in the volumes of greenhouse gas emissions in Europe till 2050 by the transport sector, it is necessary to be taken measures both in the field of planning, organization and management of the freight and passenger carriages and in the production and decommissioning processes of the rolling stock. In this regard, the purpose of the current study is to be evaluated whether the implementation of the European Green Deal is an opportunity or restriction to the development of the transport sector in EU members-states, such as Bulgaria, Romania, Croatia, Hungary, Slovakia and Slovenia, whose GDP per head is significantly lower than the EU average levels.

\section{Literature review}

There are few publications, devoted to the relationship between European Green Deal and the development of the transport sector in the scientific literature. Interesting article in this context, is that of P. Siskos et all [4], which put the accent over the methodological assessment of the cars' ecology standards in relationship to the adoption of a European strategy for decarbonisation of the economy. Through the application of the economictransportation method PRIMES-TREMOVE, the authors studied the European policy for cost and energy effectiveness, as well as the ecological impact of cars on the environment. They use the scenario method; through which they compare various standard configurations with a reference one. In conclusions, the authors summarize that the restructuring of the European automobile fleet will lead to significant decrease in the volumes of $\mathrm{CO}_{2}$ in the atmosphere, if a suitable infrastructure for usage and implementation of alternative fuels is created.

A team of authors, such as K. Hainsch, L. Goecke, C. Kemfert, P. Oei and Chr. Hirschhausen, analyses whether the sectoral measures, mentioned in the European Green Deal are relevant and sufficient for the economic sectors to achieve climate neutrality [5]. For that purpose, they use two of the models for evaluation of the energy system of Germany - GeNeSYS - MOD and anyMOD (Box). The authors come to the conclusion that Europe, incl. Germany could both respond to the provisions of the Paris Agreement and could base their energy systems entirely on renewable energy resources till 2050 at the latest. P. Oberhof and E. Fuerst in their publication, study the sustainable development of the transport sector having regard its impact over the environment [6]. The article is focused on the environmental management of the Austrian road transport companies, which provide public freight carriages or freight carriages on their own. The authors summarize that the performance of environmental information in the annual reports of transport companies, should be correlated with the long-term management strategy of the business but not to its size or sectoral affiliation. They propose to the Austrian government to set restrictions for the ecology friendliness of the transport companies, and they highlight the necessity of including the transport sector to the EU Emissions Trading System.

A. Sikora proposes a different review of the European Green Deal, as she identifies the financial and legislative challenges, set in it [7]. According to the author, the European Green Deal provides great opportunities for economic development of EU, provided that the adopted principles of solidarity, sustainable development and high environmental protection in the EU legislation are preserved. She comes to the conclusion that climate neutrality could only be achieved through involvement both of the EU member-states and the EU citizens who are agreeing to pay jointly and severely the costs for implementation of the European Climate Pact. In a close relation with the Sikora's research, it could be listed the article of C. Kemfert, who puts the focus over the protection of the climate and energy security of Europe [8]. According to the author, each member-states needs to transform its energy system in order to increase the share of renewable energy resources and to restrict the share of fossil fuels and nuclear energy. Of course, this could be achieved with the financial support of the EU through the Just Transition Fund. 
Based on the literature review, it could be concluded that no publication in the scientific literature repeats the purpose of the current research. There are articles that study the energy and environmental effectiveness of the road transport, but they do not address the issue to other modes of transport. There are publications which identify the pros and cons of the implementation of the European Green Deal, but these are correlated with energy security, financial stability and solidarity and legislative requirements, they do not explore the opportunities and restrictions of EGD to the transport sector.

\section{Priorities of the European Green Deal and status quo of the transport sector}

\subsection{European policy for transport sector development in the context of climate neutrality achievement}

As early as in 2018, the European Commission adopted a strategy, whose long-term vision is to be achieved prosperous, competitive, and climate-neutral economy [9]. Its main purpose is to respond to the Paris Agreement for reducing the greenhouse gas emissions to the atmosphere with $40 \%$ in 2030 compared to 1990 and achieving economic and social transformation of all economic sectors, dependent on fossil fuel consumption. Through the strategy, there are outlined eight scenarios, which are based on the electrification of the economic sectors, usage of alternative fuels, such as hydrogen, e-fuels and transition to circular economy. Key priority of this strategy is the insurance of environmentally friendly, safe, secure and connected mobility, accessible to all EU citizens. In this sense, the strategy puts the attention to application of electrical vehicles, usage of LNG in the short-sea shipping and shipping on inland waterways, usage of biofuels and carbon-free e-fuels in the aviation. In addition to the fleet, special attention is paid to the development of the transport infrastructure, especially to the completion of the TEN-T core and comprehensive network through ensuring interoperability amongst environmentally friendly and energy efficient modes of transport and usage of intelligent transportation systems.

In supplement to the "Clean Planet for all" strategy, in 2019 the European Commission introduced a package of specific measures - the European Green Deal - according to which the EU economy should be free of net greenhouse gas emissions till 2050 and the EU economic growth will not be based and dependent on fossil fuels [10]. The idea is to be achieved just and inclusive economy, in order the natural capital to be preserved and the welfare of the nation to be ensured. The European Green Deal presents a roadmap with key priorities for the development of the economic sectors of both the EU and the member-states, which priorities entirely respond to the UN Agenda 2030 sustainable development goals (SDGs). The transport sector is included in priority axes № 5, which purpose is to be accelerated the transition to sustainable and smart mobility. The mainstream of development of this economic sector in the next 30 years is:

$\checkmark$ Increasing the share of multimodal transportation services;

$\checkmark$ Digitalization and automation of the rolling stock and infrastructure;

$\checkmark$ Internalization of the external costs of transport;

$\checkmark$ Production and usage of alternative fuels in all transport modes;

$\checkmark$ Reducing the pollution of the atmosphere in the cities, caused by the transport sector.

It is obvious that serious changes in the organization and management of the transportation processes should be achieved on national, European, and global level. This is necessary because the transport sector has also a great significance for the achievement of 3 of the seventeen sustainable development goals [11], namely - goal 3 (ensure healthy lives and promote well-being for all at all ages), goal 9 (build resilient infrastructure, promote 
inclusive and sustainable industrialization and foster innovation) and goal 11 (make cities and human settlements inclusive, safe, resilient, and sustainable).

In accordance with the European Green Deal, at the end of 2020 the European Commission adopted a "Sustainable and smart mobility strategy", which is the main document that outlines the future development of the European transport system in order climate neutral economy to be achieved till 2050 [12]. The strategy is based on three pillars, related to - reduction of current dependence of transport sector on fossil fuels; provision of multimodal transportation services and shift to sustainable transport modes and internalization of the external costs of transport. The listed priorities are focused over ten key flagships for development of the sector:

$\checkmark$ Encourage production of zero-emission vehicles, renewable and low-carbon fuels and related infrastructure;

$\checkmark$ Creating zero-emission airports and ports;

$\checkmark$ Achieve sustainable urban and interurban mobility and protection of the population health;

$\checkmark$ Achieve green freight carriages;

$\checkmark$ Accelerated adoption of the "polluter pay principle" and the "user pay principle";

$\checkmark$ Encourage connected, cooperative and automated mobility (CCAM);

$\checkmark$ Stimulate innovations, data and artificial intelligence;

$\checkmark$ Accelerate the processes for creating the EU single transport market;

$\checkmark$ Ensure fair and just mobility for all;

$\checkmark$ Increase the safety and security of the freight and passenger carriages.

In supplement to the Sustainable and smart mobility strategy, in 2021 the European Commission presented an evaluation report of the Urban mobility package from 2013 [13]. This report puts the accent over the urban logistics, safety mobility, deployment of intelligent transportation systems in urban environment, as well as revision of the regulations, concerning the access of cars to the cities centers and connecting the urban infrastructure with the core and comprehensive TEN-T network. One of the purposes of this evaluation report is to be built $5000 \mathrm{~km}$ of bike lanes and 100 of the European cities to be climate neutral till 2030.

\subsection{Status quo of the European transport system in accordance with the European policy requirements for climate neutrality}

European transport sector contributes to 5\% increase of the GDP per annum and at the same time ensures jobs to 10 millions of people [12]. On the other hand, the transport sector (predominantly road transport) causes loss of human lives and destroys European citizens' health, especially in the member-states, whose GDP per head is significantly lower than the average GDP per head for Europe. For example, in countries like Bulgaria, Romania, Hungary and Croatia, the number of car accidents per annum is very high for the period 20102019 and this number does not decrease: Bulgaria - 660 human lives, Romania - 1960, Hungary -630 and Croatia -350 [14]. This supposes lower safety and security of the freight and passenger carriages with road transport and not sufficient application of the intelligent transportation systems to the rolling stock and relevant infrastructure. Opposite to the road transport, the safety of railway transport carriages is much more secure and the number of registered accidents in the aforementioned member-states is an evidence for that statement. In Bulgaria, the number of the registered railway incidents is 47 per annum, in Romania 178 , in Hungary -160 , Croatia - 33. Definitely, this fact is relative to achieving both the tenth priority flagship of the "Sustainable and smart mobility strategy" and the purposes of the European Green Deal. According to the provisions of the European Green Deal, till 2030 the greenhouse gas emissions from the transport sectors need to be reduced with $55 \%$, and 
till 2050 the transport sector needs to be climate neutral. In this sense, it is needed to be achieved a transformation in the conditions and requirements for licensing of the transport operators, as well as for building of new infrastructure or reconstruction of the existing infrastructure, digitalization of the transport sector, implementation of artificial intelligence and achieving circular and low-carbon transformation of the sector [15]. This will create serious problems for the small and medium sized enterprises in less developed regions, such as Bulgaria. For example, in June 2021, the number of licensed transport operators for international freight carriages are over 13200 , as $95 \%$ of them are small and medium sized enterprises [16]. Of course, to achieve climate neutrality within Europe till 2050, the European Commission provides funding through the Invest EU and Just Transition Mechanism. However, in many cases, it is necessary national co-funding which is sometimes an impossible task for many of the members-states, such as Bulgaria, Hungary, Romania, Slovakia, Croatia.

Most of the freight and passenger carriages in these member-states are still carried by road transport and the share of energy-efficient and environmentally friendly modes of transport, such as railway and inland waterway transport is insignificant. On figure 1, it is presented the share of railway and inland waterway transport as a total for the EU memberstates with GDP per head significantly lower than the average GDP per head for Europe for the period 2010-2019.

As seen from the graphic, only in Romania approximately $60 \%$ of the freight carriages are carried by energy-efficient and environmentally friendly modes of transport. The share of these carriages is the lowest in Croatia - $28 \%$, in Bulgaria, it is $46 \%$, Slovakia $-40 \%$, Slovenia $-34 \%$ and Hungary $-35 \%$. The observed trend is of decrease in the volume of the freight carriages by railway and inland waterway transport after 2017 , which fact could be perceived as an obstacle both for the reduction of the volumes of greenhouse gas emissions by the transport sector of Europe with $90 \%$ till 2050 and for the sustainable supply chain management in Europe [17].

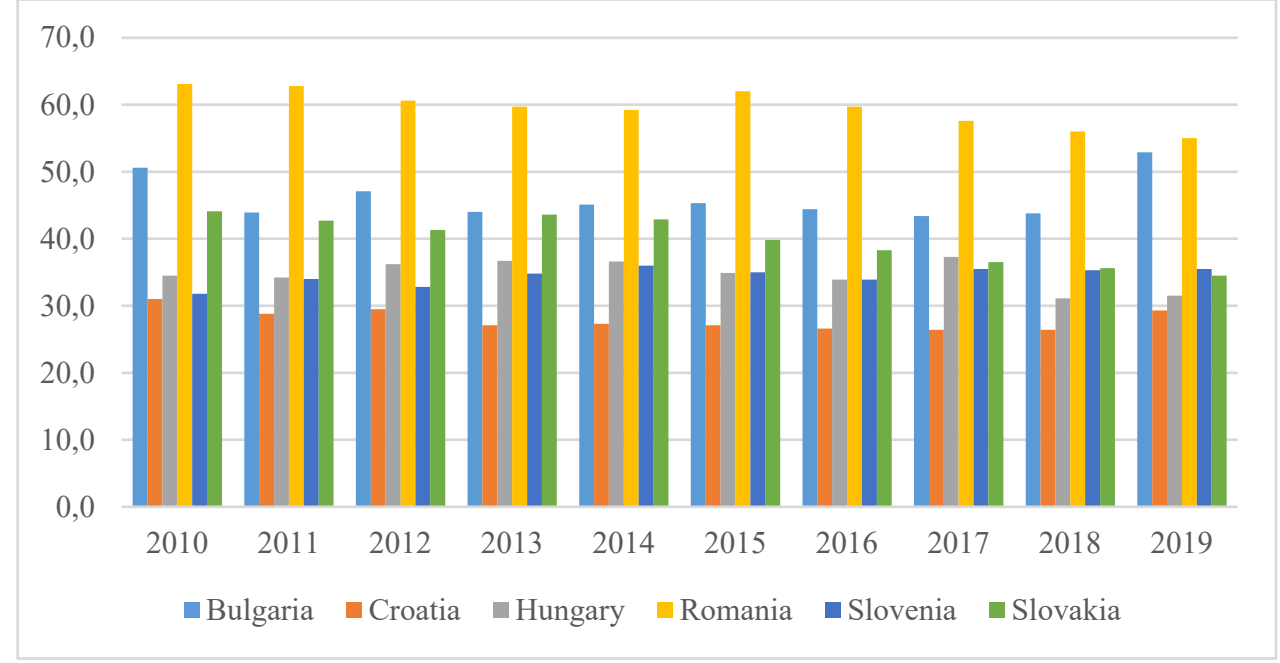

Fig. 1 Share of the freight carriages, carried by railway and inland waterway transport for the period 2010-2019

Source: EUROSTAT and calculations of the author

The data from figure 1 confirmed the publicly available statistical information about the volumes of greenhouse gas emissions in these countries. For example, 98\% of the average volumes of $\mathrm{CO}_{2}$ per annum for the period 2010-2019 are caused by the road transport sector of Slovenia [18]. In Bulgaria, the share of these emissions is $94 \%$ respectively, in Romania 
$-94 \%$, Slovakia $-92 \%$, Hungary $-96 \%$ and Croatia $-95 \%$. For the same period, the average annual volumes of $\mathrm{CO}_{2}$ from the railway, inland waterway and air transport are many times lower, as their volumes vary in the range between $0,1 \%$ and $2,1 \%$.

Another important problem, that the European transport system faces, is the implementation both of the European Green Deal and the Sustainable and smart mobility strategy, which emphasize on the usage of alternative fuels in all transport modes. On figure 2 it is presented the share of alternative fuels used by the transport sector for the period 2010 -2019 .

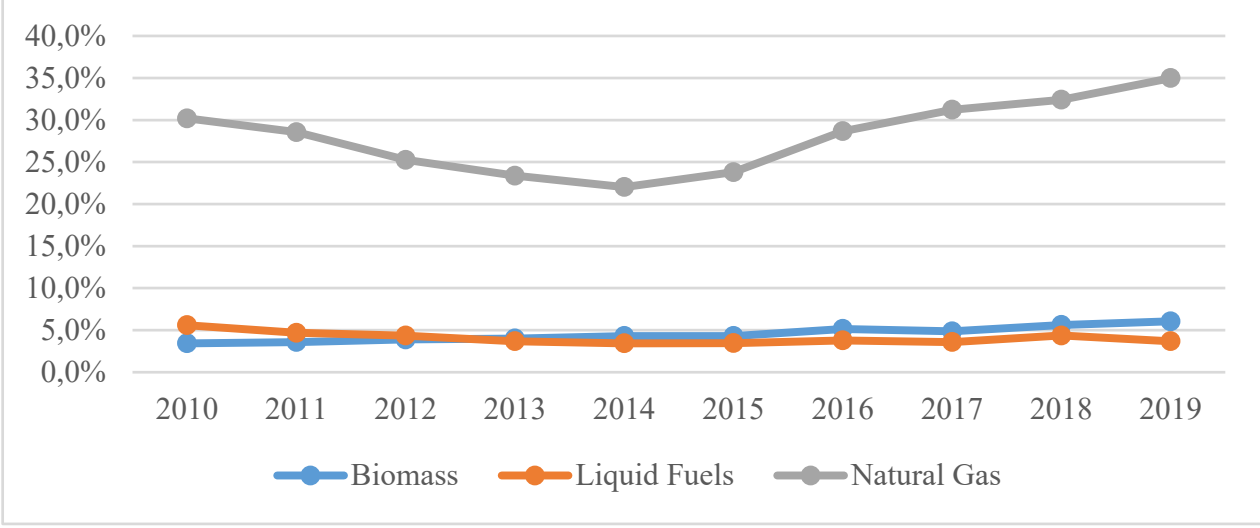

Fig. 2 Share of the alternative fuels used by the transport sector for the period 2010-2019. Source: European Pollutant Release and calculations of the author

According to the data seen on the figure above, till the end of 2019, the share of the natural gas used prevails $-35 \%$. Just over $6 \%$ of the transport operations are carried through the usage of biofuels, which share has constantly increased since 2013. The process of replacing fossil fuels with alternative ones in the transport sector will be a difficult process but at the same time efficient as there will be made savings of 9 billion euros of the import of petrol till 2030 [19]. In this regard, in the last years the main manufacturers of light and heavy duty vehicles are increasing the share of cars produced with electrical and hydrogen cells powertrains [20]. The achievement of climate neutrality in the sense of the consumed fuels by air and waterborne transport will be a difficult task because of the lack of technologies for reducing the greenhouse gas emissions and the long depreciation period of the rolling stock. However, according to the statistics of the European Union Aviation Safety Agency, the emissions of CO2 by the aviation could be reduced by up to $94 \%$ if using the Fischer-Tropsch conversion technology of agriculture residues for aviation fuel production [21]. Moreover, in 2016, the International Civil Aviation Organization (ICAO) implemented a Carbon Offsetting and Reduction Scheme for International Aviation (CORSIA), under which, the member-states will voluntarily offset their CO2 emissions from 2021 onwards. Since 01 January 2021, CORSIA is ratified by 88 countries, including Bulgaria, Croatia, Romania, Slovakia, Slovenia and Hungary [22].

Another important prerequisite for achieving climate neutrality of the transport sector till 2050, is the implementation of multimodal transportation services on the core and comprehensive TEN-T network, through interoperability of the intelligent transportation systems of all modes of transport. Main problem that arises in this sense is the equipment of separate sections of the network with communication applications and information technologies within the scope of the analyzed member-states. For example, till 2019 with the European Railway Traffic Management System (ERTMS) are equipped only 20\% of the planned kilometers of the Bulgarian section of the Orient-East/Mediterranean Transport Corridor, while in Romania, Hungary and Slovakia, these kilometers are 0\% [23]. Only in 
Slovakia, the road infrastructure along the Corridor is entirely connected $(100 \%)$ to the railway stations and inland waterway ports of the country. In the other countries, such as Bulgaria, Hungary and Romania, respectively $71 \%, 94 \%$ and $37 \%$ of the highways and express roads are linked to the railway terminals and inland waterway and maritime ports. As regards the possibility of operating multimodal transportation services by railway and air transport, the infrastructure of none of these modes of transport in the aforementioned countries allow provision of multimodal transportation services along the Orienteast/Mediterranean Transport Corridor. This implies that in order to be achieved the main priorities of the European Green Deal, the national governments of the analyzed memberstates need to ensure enough funding for the development of their national transport systems not only for the expansion of the core and comprehensive TEN-T network on their territories, but also for reduction of the volumes of greenhouse gas emissions to the atmosphere and insurance of free, just and safe mobility for their citizens.

\section{Conclusion}

The impact of the European Green Deal on the development of the European transport system is an issue, that has not been examined in detail yet. An evidence for that reason is the small number of publications in this field. The purpose of the current study was to explore whether the requirements of the European Green Deal for transformation of the economies of EU member-states and especially those with GDP per head significantly lower than the average GDP per head for Europe, could be perceived as an opportunity or as a restriction for the development of their national transport systems.

Definitely, the significant reduction of the volumes of greenhouse gas emissions in the atmosphere till 2030 and achieving climate neutrality till 2050 will have a long-term positive effect over the health and well-being of the nations, protection of the biodiversity and nature resources. However, till 2019 more than $60 \%$ of the freight and passenger transportation services are carried by road transport in countries like Bulgaria, Croatia, Slovakia and Romania, which causes over $95 \%$ of the emissions of $\mathrm{CO}_{2}$ in the atmosphere. On the other hand, the share of the used biofuels is still unsatisfactory - around $6 \%$, but this share has increased almost two times since the last decade. The share of used natural gas in short sea shipping and shipping on inland waterways is also increasing. In addition, all of the surveyed member-states have ratified the Carbon Offsetting and Reduction Scheme for International Aviation, which fact will have positive impact over the fulfillment of the third and eleventh Sustainable development goals of the United Nations Agenda 2030.

Despite this, the necessary changes in the methodology of licensing the transport operators in order to be used electrical vehicle, e-fuels and operation of green logistics, it will be an impossible task for the small and medium sized enterprises for their economic survival on the transport market (in Bulgaria, for example, $95 \%$ of the licensed road companies are small and medium sized enterprises). This will lead to termination of the economic activities of many companies and will create conditions for emergence of imperfect market structures, such as oligopoly or monopoly on the one hand and on the other - it will make difficult the process of internalization of the external costs of transport.

Till present, the transport sector of the analyzed member-states is highly dependent on the freight and passenger road carriages. This is also confirmed by the number of car accidents per annum occurred for a period of ten years (for example the number of people lives lost in Romania per year is 2000).

A serious restriction to the implementation both of the European Green Deal and the Sustainable and smart mobility strategy is the insufficient equipment of the transport infrastructure with information and communication technologies along the core and comprehensive TEN-T network. The insufficient transport connectivity amongst railway and 
road infrastructure, as well as the airports and ports will hinder the operation of multimodal transportation services and will limit the free, safe and secure mobility of the population. As a result, the impossibility to respond to the ninth sustainable development goal of UN Agenda 2030 could be an indirect negative effect of this problem.

The proposed ideas and the results achieved of the current study could be undoubtedly useful for the national governments of the surveyed member-states, especially in the preparation of their annual reports about the progress of decarbonization of the national economies and for the implementation of future strategies and policies for the development of their transport systems.

\section{References}

1. United Nations, Paris Agreement (2015), https://unfccc.int/sites/default/files/english_paris_agreement.pdf,

2. Directorate General Mobility and Transport, Statistical pocketbook 2020, (2021) https://ec.europa.eu/transport/facts-fundings/statistics/pocketbook-2020 en,

3. European Commission, Clean Power for Transport: A European alternative fuels strategy (2013), https://eur-lex.europa.eu/legalcontent/EN/TXT/PDF/?uri=CELEX:52013PC0017\&from $=\mathrm{EN}$

4. P. Siskos, P. Capros, A. De Vita, Energy Policy, 84, 22-34 (2015)

5. K. Hainsch, L. Goecke, C.Kemfert, P. Oei, Chr. von Hirschhausen, European Green Deal: Using ambitious climate targets and renewable energy to climb out of the economic crisis, DIW Weekly report, Berlin, (2020), http://dx.doi.org/10.18723/diw_dwr:2020-28-1

6. P. Oberhofer, E. Fuerst, Bus. Strat. Env., 22, 374-389 (2013)

7. A. Sikora, ERA Forum, 21, 681-697 (2021)

8. C. Kemfert, Intereconomics, 54, 353-358 (2019)

9. European Commission, A Clean Planet for all, A European strategic long-term vision for a prosperous, modern, competitive and climate neutral economy (2018), https://eurlex.europa.eu/legal-content/EN/TXT/PDF/?uri=CELEX:52018DC0773\&from=en

10. European Commission, The European Green Deal, (2019), https://eurlex.europa.eu/resource.html?uri=cellar:b828d165-1c22-11ea-8c1f01aa75ed71a1.0002.02/DOC 1\&format=PDF

11. United Nations, Department of Economic and Social Affairs, Sustainable development goals, (2021), https://sdgs.un.org/goals

12. European Commission, Sustainable and Smart Mobility Strategy - putting European transport on track for the future, (2020), https://eur-

lex.europa.eu/resource.html?uri=cellar:5e601657-3b06-11eb-b27b01aa75ed71a1.0001.02/DOC 1\&format=PDF

13. European Commission, Evaluation of the 2013 Urban Mobility Package, Commission Staff Working Document (2021), https://eur-lex.europa.eu/legalcontent/EN/TXT/PDF/?uri=CELEX:52021SC0047\&from=en

14. EUROSTAT, Road safety, (2021), https://appsso.eurostat.ec.europa.eu/nui/show.do?dataset=tran_sf_roadse\&lang=en

15. Sht. Nozharov, Identification of the Barriers to the Circular Economy-the Case of the Furniture Industry, In Digitalisation and Circular Economy: Forestry and Forestry Based Industry Implications-Proceedings of Scientific Papers, 12th Wood EMA 
Annual International Scientific Conference, 111-116 (2019),

http://www.woodema.org/proceedings/WoodEMA_2019 Proceedings.pdf\#page $=113$

16. Executive Agency "Road Transport Administration", Registry of the road freight carriers, (2021), https://rta.government.bg/images/Image/registri/mt.htm

17. Mollov, D., BAS-ERI, Economic Thought J, (5), 92-107 (2016)

18. EUROSTAT, Pollutant emissions from transport, (2021), https://ec.europa.eu/eurostat/databrowser/view/t2020_rk300/default/table?lang=en

19. European Commission, Clean Power for Transport: A European alternative fuels strategy, (2013), https://eur-lex.europa.eu/legalcontent/EN/TXT/PDF/?uri=CELEX:52013PC0017\&from=EN

20. N. Dimitrov, EJES, 4(1), 295-299 (2018)

21. European Union Aviation Safety Agency, Figures and Tables, (2021), https://www.easa.europa.eu/eaer/topics/sustainable-aviation-fuels/figures-and-tables

22. ICAO, CORSIA States for Chapter 3 State Pairs, (2020), https://www.icao.int/environmentalprotection/CORSIA/Documents/CORSIA_States_for_Chapter3_State_Pairs_Jul2020.p df

23. M. Grosch, Fourth Work Plan of the European Coordinator, DG Transport and Mobility, (2020), https://ec.europa.eu/transport/sites/default/files/oem_wp_iv.pdf 